\title{
MARÍA MAGDALENA: ENTRE EL MITO Y LA REALIDAD
}

\author{
MARIA MAGDALENE: BETWEEN MYTH AND REALITY
}

Eduardo Calcín Figueroa*

\begin{abstract}
RESUMEN
Mucho se ha dicho sobre María Magdalena (o María de Magdala) a lo largo de muchísimos años en la historia del cristianismo. Su nombre ha sido asociada a diversas imágenes bíblicas, identificada como por ejemplo con: la pecadora arrepentida, la prostituta convertida, la penitente de la rgos cabellos y abundantes lágrimas, la joven "que eligió la mejor parte" a los pies de Jesús, la mujer del frasco de alabastro que ungió al Maestro en Betania, a la que se le perdonaron sus muchos pecados porque mostró mucho amor, la que permaneció al pie de la Cruz cuando todos lo abandonaron, la que vio al Resucitado primera que todos y corrió a anunciar a todos que Jesús estaba vivo. ¿Son todas estas mujeres una misma persona? ¿Quién es María Magdalena? ¿Cuáles son las fuentes más confiables para reconstruir la figura y la vida de María Magdalena? Estas son preguntas que trataremos de responder en el presente ensayo.
\end{abstract}

\section{PALABRAS CLAVE:}

María Magdalena, Magdala, biblia, mujer, apócrifo, discípula, apóstol.

\begin{abstract}
Much has been said about Mary Magdalene (or Mary Magdalene) over the centuries in the history of Christianity. Her name has been associated with various biblical images, identified as such with the repentant sinner, the prostitute turned, the penitent with long hair and abundant tears, the young woman "who chose the better part" at the feet of Jesus, the woman of alabaster jar which blessed Jesus at Bethany, which he forgave her sins because she showed a lot of love, which remained at the foot of the Cross when all left, the first to see the risen and ran to announce to everyone that Jesus was alive are all these women the same person? Who is Mary Magdalene? What are the most reliable sources to reconstruct the shape and life of Mary Magdalene? These are questions we try to answer in this essay.
\end{abstract}

\section{KEYWORDS:}

Mary Magdalene, magdala, bible women, apocrifoc, disciple, apostle.

* Docente de la Universidad Femenina del Sagrado Corazón: ecalcin@unife.edu.pe 


\section{INTRODUCCIÓN}

María Magdalena, María de Magdala o María la Magdalena (cfr. Lc 8,2), es así llamada porque habría nacido en el pueblo de Magdala, ubicada a la orilla del mar de Galilea, o lago de Tiberiades. Su nombre se encuentra asociado a diversas figuras bíblicas como: la pecadora arrepentida, la prostituta convertida, la penitente que lavo los pies de Jesús con sus lágrimas y los secó con sus cabellos, la joven "que eligió la mejor parte" a los pies de Jesús, a la que se le perdonaron sus muchos pecados porque mostró mucho amor, la que permaneció al pie de la Cruz cuando todos lo abandonaron, la que vio al Resucitado primera que todos y corrió a anunciar a todos que Jesús estaba vivo. Pero, de todas estas la que más se acerca a lo que verdaderamente fue ella se encuentra en el testimonio del evangelista Juan al presentarla como la "discípula" y "apóstol de los apóstoles".

\section{María Magdalena en la literatura canónica y no canónica}

Los Evangelios del Nuevo testamento -"evangelios canónicos"--, son las fuentes más antiguas que podemos consultar sobre María Magdalena; por consiguiente, más confiables. Son libros de la segunda mitad del siglo primero. El Evangelio según San Marcos, el más antiguo, se redactó entre el 70-75 dC; el Evangelio según San Mateo (75-80 dC), el Evangelio según San Lucas (75$80 \mathrm{dC}$ ), y el Evangelio según San Juan (85-90 dC). Estas fuentes más antiguas que la mencionan no tratan acerca de ella, sino acerca de Jesús, tanto su vida pública como su pasión, muerte y resurrección. Los evangelistas narran estos sucesos desde una fe pospascual, ordenándolos de manera distinta bajo criterios eminentemente pastorales; por ello, incluso no todos presentan todos y cada uno de los hechos y milagros; sino lo hacen de una manera distinta en función de los destinatarios mismos a quienes va dirigido el evangelio.

Desde esa perspectiva, no tenemos por qué tratar de encontrar certezas históricas en los sucesos que acontecieron ni datos exactos sobre ciertos personajes de la biblia. Porque como veremos, lo que la biblia presenta son reflexiones en torno a hechos que buscan inducir al lector a un encuentro personal y comunitario con Cristo Resucitado.

Por otra parte, nos encontramos también con otros escritos llamados "evangelios apócrifos", como: el Evangelio de Pedro, el Evangelio de Judas, el Evangelio de Tomás, el Evangelio de Felipe y el Evangelio de María Magdalena. Estos evangelios, si bien surgieron en los primeros siglos de la Iglesia, difieren de los "canónicos" tanto por su contenido como por su forma y procedencia. Los apócrifos dan la impresión de ser Escritura Sagrada, tanto por el lenguaje que emplean como por los temas que tratan. Muchos de ellos se presentan como obras de algún personaje importante; un Patriarca, un Profeta o un Apóstol. Se presentan como obras que supuestamente habían estado perdidas por algún tiempo o cuyos mensajes habían sido escondidos por tratarse de "revelaciones secretas" (Arens, 1990). Algunos fueron escritos para comunidades judeocristianas, otros fueron reelaborados o compuestos por grupos gnósticos, por ejemplo el Evangelio de Tomás.

En el Evangelio de Pedro se menciona a María Magdalena en su papel de testigo de la resurrección de Jesús: A la mañana del domingo, María la de Magdala, 
discípula del Señor -atemorizada a causa de los judíos, pues estaban rabiosos de ira, no había hecho en el sepulcro del Señor lo que solían hacer las mujeres por sus muertos queridos-, tomó a sus amigas consigo y fue al sepulcro en que había sido depositado. En otros dos textos apócrifos de origen gnóstico, como el Evangelio de Tomás y el Evangelio de Felipe, María Magdalena aparece mencionada como discípula cercana a Jesús. En el Evangelio de Tomás hay dos menciones de una tal Mariham (log 21 y 114) quien sería nuestra María Magdalena. Así, encontramos el siguiente fragmento: Simón Pedro les dijo: «iQue se aleje Mariham de nosotros!, pues las mujeres no son dignas de la vida». Dijo Jesús: «Mira, yo me encargaré de hacerla macho, de manera que también ella se convierta en un espíritu viviente, idéntico a vosotros los hombres: pues toda mujer que se haga varón entrará en el reino del cielo». Mientras que, en el evangelio de Felipe se considera a María Magdalena como la "compañera" de Jesús; es decir, su pareja sentimental, ya que la expresión "compañera" era usada en esos tiempos para designar a la novia: Tres (eran las que) caminaban continuamente con el Señor: su madre María, la hermana de ésta y Magdalena, a quien se designa como su compañera [roıvwvoc]. María es, en efecto, su hermana, su madre y su compañera.

Otra importante referencia sobre ella lo encontramos en el evangelio de María Magdalena -escrito entre los años 60 y 80 dC-, texto del que se conservan sólo dos fragmentos griegos del siglo III y otro, más extenso, en copto, del siglo V. En el texto copto se encuentra un diálogo entre los apóstoles sobre lo acontecido con Jesús -mencionado como "el Salvador"-, y la suerte que ellos correrían entre las gentes. Interviene Mariam dando a conocer una visión y un diálogo que mantuvo con Jesús y que los demás desconocen. Posteriormente los tres apóstoles (Andrés, Pedro y Mateo, llamado Leví) discuten acerca del testimonio de María Magdalena sobre Jesús y desconfían de la revelación que hace, sólo es Leví (el apóstol Mateo) quien la defiende: Ellos, sin embargo, estaban entristecidos y lloraban amargamente diciendo; "¿Cómo iremos hacia los gentiles y predicaremos el evangelio del reino del hijo del hombre? ¿Si no han tenido con Él ninguna consideración, cómo la tendrán con nosotros?".... evangelio.... del Salvador... Leví dice a Pedro: "Siempre tienes la cólera a tu lado, y ahora mismo discutes con la mujer enfrentándote con ella. Si el Salvador la ha juzgado digna, ¿quién eres tú para despreciarla? De todas maneras, Él, al verla, la ha amado sin duda. Avergoncémonos más bien, y, revestidos del hombre perfecto, cumplamos aquello que nos fue mandado. Prediquemos el evangelio sin restringirnos ni legislar, (sino) como dijo el Salvador". Terminando Leví estas palabras, se marchó y se puso a predicar el evangelio según María.

Estos textos apócrifos han llevado a especular en torno a una posible relación entre Jesús y María Magdalena, dando lugar a una leyenda que circuló ampliamente durante la Edad Media y que ha sido explotado por el cine, como por ejemplo en 1988, M. Scorcese adaptó la novela de Kazantzakis en su película "La última tentación de Cristo", donde se presenta la escena en que Jesús se imagina a sí mismo casándose con María Magdalena en lugar de muriendo en la cruz. Y en ámbito literario, Dan Brown en 2003, publicó "El Código Da Vinci", donde entremezcla los géneros de suspenso y esoterismo y nueva Era, con una teoría de conspiración relativa al Santo Grial y al papel de María Magdalena en el cristianismo. En tal libro, el Opus 
Dei, estaría presuntamente involucrado en una conspiración para encubrir la verdadera historia de Jesucristo, quien se habría casado con María Magdalena y habría tenido descendientes que llegaron a Francia. La teoría expuesta literariamente por su autor, juega con la idea que el cristianismo habría vivido conscientemente dentro de una mentira fraguada por la Iglesia católica durante los últimos dos mil años. La obra despertó una gran cantidad de críticas en el ámbito académico porque se manejan supuestos datos históricos, geográficos, religiosos y culturales que no están avaladas con pruebas empíricas o argumentos sólidos.

\section{María Magdalena en la historia}

María Magdalena, María de Magdala o María la Magdalena (cfr. Lc 8,2), es así llamada porque se dice que nació en el pueblo de Magdala, ubicada a la orilla del mar de Galilea, o lago de Tiberíades, aunque el nombre de esta ciudad no es mencionada en el Nuevo Testamento. En el Evangelio según San Marcos se le identifica con la ciudad de Dalmanutá (cfr. Mc 8,10) y en el Evangelio según San Mateo con Magadán (cfr. Mt 15,39).

Estos quisieron decir Magdala, se trata del lugar al cual cruzaron en barca Jesús y sus discípulos después de alimentar a cuatro mil personas con siete panes y unos cuantos peces (cfr. Mt 15,3238; Mc 8,1-9). Actualmente, al norte de Tiberiades está la pequeña ciudad de Mejdel o Migdal, nombre que podría derivar de Magdala. Es una hipótesis que concuerda muy bien con los testimonios de los peregrinos antiguos, que ubican a Magdala entre Tiberíades y Cafarnaúm.

María Magdalena vivió en una época en la que Israel estaba ocupado por las fuerzas romanas. Y en donde la mujer era infravalorada en el orden ético y jurídico. La mujer aparece en el mismo plano que los paganos y las personas sin formación o que los niños y los esclavos. La mujer era una mercancía que se compraba como se podía adquirir a un esclavo. Cuando la mujer judía en los tiempos de Jesús salía de casa, llevaba la cara cubierta con dos velos y una diadema sobre la frente con cintas colgantes hasta la barbilla y una malla de cordones y nudos que no permitían ver los rasgos de la cara. Si una mujer salía de casa sin llevar la cara cubierta atentaba contra las costumbres de la época y el marido tenía el derecho, incluso el deber de despedirla. Ya el Antiguo testamento ve en ella un símbolo del mal, circunstancia que obedece a lo visto en Gn 3; dado que, Eva fue el origen del pecado. Dándose así, una desigualdad de los sexos en el plano antropológico y ético

Por ejemplo, cuando los escribas y fariseos llevan ante la presencia de Jesús quien está predicando en el Templo (cfr. In 8, 1-11) una mujer que ha sido sorprendidaen el acto mismo del adulterio, y que por eso, según la ley de Moisés, debe ser lapidada; la ausencia notable es la del varón. Después de todo, los dos debieron ser sorprendidos juntos y él también debería ser lapidado: Si un hombre comete adulterio con la mujer de su prójimo, será muerto tanto el adúltero como la adúltera.

Por otra parte, la mujer no podía presidir los actos públicos religiosos, hacer la lectura de la Torá o participar en la fiesta de Pascua. En esta situación, la mujer estaba marginada del ámbito legal, social y religioso. Su presencia se reducía al cuidado de la casa y los hijos. No tiene nada que hacer fuera de la casa y, si se ve obligada a salir, tiene que guardar el anonimato más completo y cubrirse por tanto con un velo. Si se inicia una conversación, por ejemplo, 
para preguntar alguna cosa, hay que responderle lo más brevemente posible; no hay que dirigirle nunca la palabra, ni siquiera para saludarla.

Esta panorámica es importante considerarla para hacer una reconstrucción de la figura de María Magdalena, valorar la actitud de Jesús frente a la mujer y el rol protagónico que jugará ésta en la naciente comunidad cristiana.

Es curioso que a María Magdalena no se la identifique por sus lazos familiares, como ocurre con las otras Marías, por ejemplo: María la madre de Jesús, María la madre de Santiago, María la hermana de Marta y Lázaro, María la de Cleofás. A María Magdalena no se le llama con el nombre de un padre, un esposo, un hijo o un hermano o hermana. Tal vez sea que estaba sola, su familia no era conocida o ¿era una mujer de la vida? : No hay razón para asociar a la "mujer pecadora pública" (cfr. Lc 7, 36-50) con María Magdalena. La razón tendría que ver tal vez con la cercanía con aquel pasaje en el que Lucas presenta expresamente a la Magdalena, en el siguiente párrafo: ....María, llamada Magdalena, de la que habían salido siete demonios (Lc 8, 2).

Todo parece indicar que dicha asociación, bastante forzada, es debida a la Homilía 33 del Papa San Gregorio I Magno, pronunciado en el año 591, según la cual: La que Lucas llama pecadora y Juan, María, creemos que es la María de la que según Marcos fueron echados siete demonios. ¿Y qué si no todos los vicios significan esos siete demonios? Esta presuposición apresurada ha conllevado a distorsionar la figura y el papel que desempeñó María Magdalena como "discípula" del Señor.

Por otra parte, no hay razón para asociar a las otras figuras femeninas que aparecen en el texto neotestamentario con María Magdalena como son:

- La mujer adúltera a la que Jesús salva de la lapidación, en un episodio que sólo relata el evangelio según san Juan (cfr. Jn 8, 3-11).

- La mujer que unge con perfumes los pies de Jesús y los seca con sus cabellos antes de su llegada a Jerusalén según los evangelios sinópticos (cfr. Mt 26, 6-13; Mc 14, 3-8; Lc 7, 3550) cuyo nombre no se menciona. Según Marcos y Mateo, sin embargo, la unción tuvo lugar en Betania, "en casa de Simón el leproso", lo que ha llevado a identificar a esta mujer a su vez con María de Betania.

- María de Betania hermana de Lázaro, a la que se atribuye en el evangelio de Juan la iniciativa antes mencionada (cfr. In 12, 1-8) y que aparece en otros conocidos pasajes del cuarto evangelio, como la resurrección de Lázaro (cfr. Jn 11, 20-30). Se identifica también con la María del episodio de la disputa entre Marta y María.

¿Quién es María Magdalena? ¿Qué sabemos de ella? Según los evangelios sinópticos sabemos que ella está entre las mujeres que acompañan a Jesús: Entre ellas estaban María Magdalena, María la madre de Santiago y de José, y la madre de los hijos de Zebedeo (cfr. Mt 27,56); ella fue a la sepultura: María Magdalena y María la de José se fijaban dónde era puesto (cfr. Mc 15,47); y Lucas hace notar que era discípula después de ser curada al ser expulsada de ella siete demonios: Y sucedió a continuación que iba por ciudades y pueblos, proclamando y anunciando la Buena Nueva del Reino de Dios; le acompañaban los Doce y algunas mujeres que habían sido curadas de espíritus malignos y enfermedades: María, llamada Magdalena, de la que 
habían salido siete demonios (cfr. Lc 8,1-2). El evangelista Juan la describe como una de las personas más cercanas a Jesús; pues estuvo junto a la cruz con los familiares de Jesús: Junto a la cruz de Jesús estaban su madre y la hermana de su madre, María, mujer de Cleofás y María Magdalena (cfr. Jn 19,25).

El Nuevo testamento nos presenta a María Magdalena como "discípula" como una de la más cercana al grupo de los Doce. Así, los doce apóstoles son llamados "discípulos" (cfr. Mt 10, 1).Yson "discípulos" todos aquellos que siguen a Jesús. Estos discípulos fueron numerosos (cfr. Lc 6, 18; 19, 37; In 6, 60). Por eso, a partir del capítulo 6 de los Hechos de los Apóstoles, se da la denominación de "discípulo" a todo creyente, independientemente que conociera o no a Jesús durante su vida terrena (cfr. Hch 6, 1s; 9, 10-26).

Por consiguiente, no existe la menor dificultad para poder reconocer como discípulas a las mujeres que acompañaron a Jesús muy de cerca. Pero, María Magdalena es además testigo clave de la muerte y sepultura de Jesús, de la tumba vacía y su resurrección.

El evangelista Juan es el único quien hace hablar a María Magdalena dirigiéndose a los discípulos que había visto al Señor (cfr. Jn 20,18). Mientras que en los otros evangelios no se reproducen ninguna de sus palabras sino que simplemente relatan que ella contó lo que había visto y oído en la tumba vacía (cfr. Mt 28,8; Mc, 16, 11; Lc 24,9-11).

En cuanto al contenido, en los evangelios sinópticos los discípulos deben ir a Galilea (cfr. Mt 26,32; Mc 14,28). Es el cumplimiento de la promesa que Jesús les dio antes de su muerte. Los discípulos deben aferrase de lo que Jesús les había enseñado en Galilea; entonces lo verán.
En el evangelio según san Lucas se trata de un recuerdo (cfr. Lc 24,6); las mujeres recuerdan que Jesús había predicho su sufrimiento, muerte y resurrección como algo que tenía que suceder. Y en el evangelio según san Juan, se trata de un llamado a ser sostenidos por la presencia espiritual de Jesús (cfr. Jn 17).

Los evangelistas siguen caminos muy diferentes al interpretar la función de María Magdalena. Así, en el evangelio según san Mateo, su mensaje es para los once discípulos, quienes junto con Judas simbolizan a las doce tribus de Israel. Su mensaje tiene consecuencias: los once efectivamente van a Galilea. El evangelista Lucas deja en claro que María Magdalena entrega su mensaje por propia iniciativa "a los once y todos los demás".

Su mensaje produce un efecto contrario: "no les creyeron". Lo que las mujeres dicen es visto como desatino (cfr. Lc 24,11). Mientras, que en el evangelio según san Juan, el mensaje de María Magdalena, es de gran importancia y no sólo para los once discípulos, sino para todos los que aceptan a Jesús como la luz del mundo (cfr. In 1,18).

\section{CONCLUSIÓN:}

Podemos concluir afirmando que el evangelista Mateo presenta a María Magdalena como "discípula" y apóstol de los apóstoles. El evangelista Lucas deja notar que las mujeres son "discípulas", pero que no han sido llamadas al apostolado como los Doce discípulos varones. El evangelista Juan presenta a María Magdalena específicamente como discípula y apóstol. Y el evangelista Marcos llama a sus lectores a ser no sólo discípulos, sino también apóstoles. Y eso se aplica tanto a varones como a mujeres, según le ejemplo de Pedro y María Magdalena. 


\section{REFERENCIAS:}

ARENS, E. (1989) Los evangelios ayer y hoy. Lima, Paulinas.

ARENS, E. (1990) La biblia sin mitos. 2da edición, Lima, Paulinas.

CASES, E. (2004) Mujeres valientes. Meditación sobre las mujeres en el evangelio. 4ta edición, Pamplona, Eunsa.

DE BOER, E. (2004) María Magdalena, más allá del mito. Buenos Aires, Lumen.
DUMAIS, M.(1987) Las mujeres en la Biblia. Madrid, Paulinas.

JEREMIAS, J. (1977) Jerusalén en los tiempos de Jesús. Madrid, ed. Cristiandad.

SAULNIER, Ch.-ROLLAND, B. (2000) Palestina en los tiempos de Jesús. 13va ed, Navarra, ed. Verbo Divino. 